\title{
Lung perfusion studies after detachable coil occlusion of persistent arterial duct
}

\author{
N Sreeram, M Tofeig, K P Walsh, P Hutter
}

\begin{abstract}
Objective-To evaluate relative lung perfusion following complete occlusion of persistent arterial duct with detachable Cook coils.

Methods-Ductal occlusion using detachable coils was performed in 35 patients (median age 3.9 years, range 0.5 to $16 ; 32$ native ducts, three patients with previous devices). If the duct could be crossed with a 0.035 inch guidewire and a $4 \mathrm{~F}$ catheter after coil implantation, a further coil was implanted. Between one and seven coils were used (median two).

Results-Complete ductal occlusion was confirmed by echocardiography 24 hours after the procedure in all patients. Lung perfusion scans were performed three months after the procedure in 33 of 35 patients (two older patients with a single coil each did not attend). Decreased perfusion to the left lung (defined as $<40 \%$ of total lung flow) was observed in only one patient, who had previously had a $17 \mathrm{~mm}$ Rashkind umbrella implanted. There was no correlation between left lung perfusion and peak left pulmonary artery Doppler velocities $(r=0.27$ and $p=0.125$ for the entire group; $r=0.29$ and $p=0.124$ after excluding patients with previous devices).

Conclusions-Coil occlusion is effective in achieving complete closure of the duct. An aggressive approach using multiple coils did not compromise perfusion to the left lung.

(Heart 1999;81:642-645)
\end{abstract}

Key words: arterial duct; coil occlusion; lung perfusion

Transcatheter occlusion of a persistent arterial duct can be achieved with the use of several devices. The major drawbacks of the umbrella occluders are persistence of a shunt for up to several years after the procedure in some patients, and compromise of flow to the left pulmonary artery. ${ }^{1-3}$ The value of Doppler echocardiography in assessing the presence and severity of left pulmonary artery stenosis following duct occlusion is unclear. ${ }^{4}$

Coil implantation using single or multiple coils has been shown to be more effective than umbrella occluders in achieving complete occlusion at short term follow up..$^{5-7}$ The smaller delivery catheters allow safe implantation of multiple coils during a single procedure. The use of detachable coils of different sizes has the added advantage that the coil can be positioned to straddle the arterial duct with the numbers of coil loops on the pulmonary and aortic sides being tailored to the length and morphology of the duct. We describe a prospective study of the use of Cook detachable coils for duct occlusion, and the results of lung perfusion studies three months after the procedure.

\section{Methods}

Thirty five patients (18 female, 17 male), underwent coil occlusion of a persistent arterial duct at two centres (Utrecht and Liverpool), using one or more coils (table 1). The median age of patients with native ducts $(n=32 ; 16$ male, 16 female) was 3.5 years (range 0.5 to 16), and median weight was $18 \mathrm{~kg}$ (7 to 49). The median minimum duct diameter on angiography was $2.1 \mathrm{~mm}$ (1.3 to 5), and the median pulmonary to systemic flow ratio ( $\mathrm{Qp} / \mathrm{Qs})$ was 1.7 (1.1 to 3.0). Duct size and morphology (using the classification of Krichenko et $a l^{8}$ ) were determined by aortography before the occlusion procedure. Qp was calculated using the average of the oxygen saturations in the two branch pulmonary arteries.

In the initial period of using coils (the first 15 patients), ducts with a minimum diameter of $>4 \mathrm{~mm}$ were excluded from coil occlusion, and in two such patients a $17 \mathrm{~mm}$ Rashkind double umbrella was used. Thereafter, duct size was not a criterion for exclusion from coil occlusion, and the patient series was consecutive.

Two patients had undergone implantation of a $17 \mathrm{~mm}$ Rashkind device 12 months previously, and one patient had had two previous umbrella devices. One other patient had an associated coarctation of the aorta, which was balloon dilated concurrently with duct closure.

Informed consent was obtained before all procedures, and the study protocol was approved by the institutional review board.

TECHNIQUE OF COIL OCCLUSION

The technique of detachable coil occlusion has been described previously. ${ }^{9}$ Briefly, the duct was crossed in the anterograde or retrograde direction using $4 \mathrm{~F}$ or $5 \mathrm{~F}$ catheters. Initial coil diameters were chosen as follows: if the minimum diameter of the duct was $<2 \mathrm{~mm}$, a $5 \mathrm{~mm}$ diameter coil was implanted; if the diameter was $>2 \mathrm{~mm}$ an $8 \mathrm{~mm}$ diameter coil was implanted. The number of loops (five loops or three loops for the $5 \mathrm{~mm}$ coil, and three, four, or five loops for the $8 \mathrm{~mm}$ coil) was determined by the length and morphology of the duct. Coils were implanted so that the minimum amount (usually 1 to 1.5 loops) of the coil was located in the pulmonary arterial side of the duct. The remaining loops were 
formed in the duct and on the aortic side. If initial deployment was unsatisfactory, the coil was withdrawn into the delivery catheter, and the implantation procedure repeated.

If the duct could be recrossed using a flexible 0.035 inch diameter guidewire after implantation of the initial coil, a $4 \mathrm{~F}$ catheter was advanced over the wire and a second coil implanted. The procedure was only terminated when the duct could no longer be crossed by the guidewire and catheter.

Follow up Doppler echocardiography was performed 24 hours and three months after the procedure.

LUNG PERFUSION SCINTIGRAPHY

At the three month follow up, outpatient lung perfusion scans were performed using an intravenous injection of ${ }^{99} \mathrm{Tc}^{\mathrm{m}}$ labelled macroaggregated albumin and a gamma camera. The labelled albumin was injected at a dose of 1.2 $\mathrm{MBq} / \mathrm{kg}$ body weight through a peripheral vein, in the supine position. A minimum dose of 10 $\mathrm{MBq}$ was injected. Static images were acquired for a total of 200000 counts wherever possible. If the child was not cooperative 100000 counts were acquired. Four views were obtained in the posterior, right and left posterior oblique, and anterior positions. Identical methods were adopted for performing lung perfusion studies in both laboratories. Ventilation scans were not performed simultaneously.
STATISTICAL ANALYSIS

Data are expressed as mean (SD) and range. Comparison of continuous data between groups was performed with the Student's $t$ test. Comparison of nominal data was performed using Pearson's $\chi^{2}$ statistic. Correlations between continuous variables was evaluated by the Pearson product-moment correlation coefficient. A p value of $<0.05$ was considered significant. Multivariate analysis was performed using logistic regression.

\section{Results}

The duct was successfully occluded in all 35 patients; 16 needed one coil, 11 needed two, three needed three, three needed four, and one each needed five and seven coils. None of the patients had a residual shunt at discharge from hospital 24 hours after the procedure. Coil protrusion into the pulmonary trunk and left pulmonary artery was assessed qualitatively (present or absent) by cross sectional echocardiography using multiple views, and was considered to be present in 13 of the 32 patients with native ducts. The three patients who had had previous devices for duct occlusion are described separately. Increasing minimum duct diameter was associated with an increase in the number of coils used to achieve occlusion $(\mathrm{p}<0.001)$. Coil protrusion into the left pulmonary artery was more common in patients with multiple coils $(p=0.0001)$. When three or more coils were used, coil protrusion into the left pulmonary

Table 1 Study data

\begin{tabular}{|c|c|c|c|c|c|c|c|c|c|c|}
\hline Case & $\begin{array}{l}\text { Age } \\
\text { (months) }\end{array}$ & Sex & $\begin{array}{l}\text { Weight } \\
(\mathrm{kg})\end{array}$ & $\begin{array}{l}\text { Minimum } \\
\text { duct } \\
\text { diameter } \\
(\mathrm{mm})\end{array}$ & Type & $Q p / Q s$ & $\begin{array}{l}\text { Coils } \\
\text { (n) }\end{array}$ & $\begin{array}{l}\text { LPA } \\
\text { protrusion }\end{array}$ & $\begin{array}{l}\text { LPA Doppler } \\
(\mathrm{m} / \mathrm{s})\end{array}$ & $\begin{array}{l}\text { Left lung } \\
\text { perfusion }\end{array}$ \\
\hline 1 & 6 & $\mathrm{~F}$ & 7.3 & 1.4 & A & 1.5 & 1 & No & 1.3 & $41 \%$ \\
\hline 2 & 65 & $\mathrm{M}$ & 18 & 3.9 & C & 1.9 & 3 & Yes & 1.7 & $44 \%$ \\
\hline 3 & 38 & $\mathrm{~F}$ & 18 & 4.2 & A & 2.7 & 4 & Yes & 1.9 & $46.2 \%$ \\
\hline 4 & 71 & M & 21.7 & 1.7 & A & 1.4 & 1 & No & 1.2 & $46.2 \%$ \\
\hline 5 & 84 & $\mathrm{~F}$ & 20.1 & 1.6 & $\mathrm{E}$ & 1.4 & 1 & No & 1.3 & $44.1 \%$ \\
\hline 6 & 26 & $\mathrm{~F}$ & 15.5 & 1.8 & $\mathrm{E}$ & 1.3 & 1 & No & 1.4 & $44.2 \%$ \\
\hline 7 & 62 & M & 23.5 & 2.5 & A & 2.1 & 2 & Yes & 1.5 & $43.9 \%$ \\
\hline 8 & 11 & $\mathrm{~F}$ & 10.6 & 1.3 & A & 1.2 & 1 & No & 1.4 & $44.5 \%$ \\
\hline 9 & 110 & M & 25 & 1.3 & A & 1.3 & 1 & No & 1.1 & No scan \\
\hline 10 & 14 & $\mathrm{~F}$ & 10.1 & 1.3 & $\mathrm{E}$ & 1.2 & 1 & No & 1.3 & $44 \%$ \\
\hline 11 & 15 & $\mathrm{~F}$ & 11 & 2.9 & A & 2.2 & 2 & No & 1.4 & $46.2 \%$ \\
\hline 12 & 109 & $\mathrm{~F}$ & 28 & 1.7 & A & 1.6 & 2 & No & 1.5 & $44.7 \%$ \\
\hline 13 & 11 & M & 8 & 2.1 & A & 2 & 2 & Yes & 1.6 & $43.8 \%$ \\
\hline 14 & 11 & $\mathrm{~F}$ & 9 & 2.3 & A & 2.1 & 3 & Yes & 1.9 & $41.9 \%$ \\
\hline 15 & 109 & $\mathrm{~F}$ & 31 & 2.1 & A & 1.8 & 2 & No & 1.4 & $44.8 \%$ \\
\hline 16 & 74 & $\mathrm{~F}$ & 24.9 & 1.8 & A & 1.4 & 1 & No & 1.3 & $48.5 \%$ \\
\hline 17 & 18 & $M$ & 8 & 2.7 & A & 1.9 & 2 & Yes & 1.4 & $44 \%$ \\
\hline 18 & 18 & M & 8.6 & 1.7 & A & 1.3 & 1 & No & 1.3 & $45.2 \%$ \\
\hline 19 & 61 & M & 22 & 2.2 & A & 1.9 & 2 & No & 1.4 & $45.1 \%$ \\
\hline $20^{\star}$ & 37 & M & 15 & 5.5 & A & 1.5 & 1 & No & 1.5 & $44.5 \%$ \\
\hline $21 \dagger$ & 192 & $\mathrm{~F}$ & 49 & 1.7 & $\mathrm{E}$ & 1.1 & 1 & No & 1.2 & No scan \\
\hline 22 & 8 & M & 9 & 2.1 & A & 1.9 & 2 & No & 1.3 & $44.8 \%$ \\
\hline 23 & 18 & $\mathrm{~F}$ & 12 & 3.6 & A & 2.2 & 3 & Yes & 1.8 & $42.7 \%$ \\
\hline 24 & 28 & $\mathrm{~F}$ & 11 & 4.1 & A & 2.9 & 4 & Yes & 1.6 & $41 \%$ \\
\hline 25 & 69 & M & 27 & 2.1 & B & 1.7 & 1 & Yes & 1.4 & $44.3 \%$ \\
\hline 26 & 22 & M & 7.4 & 1.9 & A & 1.6 & 1 & No & 1.4 & $47 \%$ \\
\hline 27 & 96 & $\mathrm{~F}$ & 23.8 & 4.5 & A & 2.5 & 4 & Yes & 1.4 & $44.1 \%$ \\
\hline 28 & 99 & $\mathrm{~F}$ & 23.1 & 4.9 & C & 2.7 & 5 & Yes & 1.9 & $46 \%$ \\
\hline 29 & 79 & M & 24 & 1.4 & A & 1.2 & 1 & No & 1.3 & $44.2 \%$ \\
\hline 30 & 36 & $M$ & 18 & 1.7 & A & 1.6 & 1 & No & 1.2 & $44.1 \%$ \\
\hline 31 & 47 & M & 19.5 & 1.9 & D & 1.8 & 2 & No & 1.5 & $42.9 \%$ \\
\hline 32 & 6 & M & 7 & 2.3 & A & 2.2 & 2 & Yes & 1.6 & $45.1 \%$ \\
\hline 33 & 66 & M & 22 & 5.0 & A & 3 & 7 & Yes & 1.9 & $41 \%$ \\
\hline $34 \ddagger$ & 74 & $\mathrm{~F}$ & 25 & 5.1 & B & 1.2 & 1 & Yes & 1.7 & $37 \%$ \\
\hline $35 \Phi$ & 51 & $\mathrm{~F}$ & 21 & 5.5 & B & 1.5 & 2 & Yes & 1.9 & $45.6 \%$ \\
\hline
\end{tabular}

^Previous $17 \mathrm{~mm}$ Rashkind umbrella device; +Concomitant balloon angioplasty of coarctation; $¥$ Previous $17 \mathrm{~mm}$ Rashkind umbrella device; \Two previous devices: $12 \mathrm{~mm}$ Rashkind umbrella and $15 \mathrm{~mm}$ adjustable button device. 


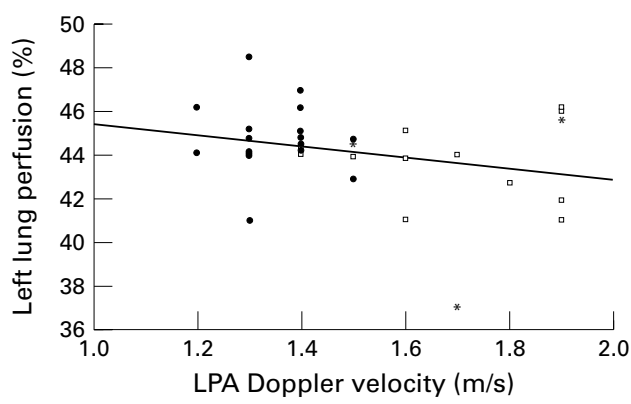

Figure 1 Scatter diagram of left lung perfusion as percentage of total lung flow (y axis) and peak left pulmonary artery (LPA) Doppler velocity in $\mathrm{m} / \mathrm{s}$ ( $x$ axis). Filled symbols denote patients without coil protrusion into the left pulmonary artery on cross sectional echocardiography, empty symbols denote patients with coil protrusion. Asterisks denote patients with previous devices implanted in the duct. The line represents the least squares regression line $(r=0.27 ; p=0.125)$. Formula: $y=-2.5+47.8(95 \%$ confidence interval of coefficient: -5.7 to $0.73 ; 95 \%$ confidence interval of constant: 43.0 to 52.6).

artery was always present. The number of coils used did not depend on duct morphology. There was also no statistical association between the number of coils used and the patient's age or weight. In a multivariate analysis using logistic regression, the minimum duct diameter was the only determining factor for coil protrusion into the left pulmonary artery.

Coil protrusion into the left pulmonary artery was associated with a higher peak left pulmonary artery Doppler velocity: $1.66(0.2)$ $\mathrm{m} / \mathrm{s}$ in patients with coil protrusion $v 1.33$ $(0.11) \mathrm{m} / \mathrm{s}$ in patients without coil protrusion $(\mathrm{p}<0.001)$. Lung perfusion scintigraphy showed that no patient had decreased perfusion of the left lung (defined as $<40 \%$ of total lung flow). This value was chosen on the basis of the study by Dessy et al. ${ }^{3}$ The mean percentage of pulmonary flow directed to the left lung was $44.3(1.7) \%$ (range $41 \%$ to $49 \%$ ). Although patients with coil protrusion into the left pulmonary artery tended to have lower values for left lung perfusion (fig 1), this was not statistically significant: $43.7(1.7) \%$ in patients with coil protrusion $v 44.8(1.6) \%$ in patients without coil protrusion $(\mathrm{p}=0.08)$.

Two patients with a single coil each did not attend for lung perfusion studies. The only patient with left pulmonary artery perfusion of $<40 \%$ had previously had a $17 \mathrm{~mm}$ Rashkind umbrella implanted, and a single coil was used to abolish the residual shunt. No lung perfusion studies had been performed before coil implantation. Two other patients with previous devices (table 1) had normal values for left lung perfusion (44.5\% and $45.6 \%$ respectively). Thus in patients without a previous umbrella occluder in the duct the prevalence of diminished left lung perfusion was $0 / 30$ (95\% confidence interval $0 \%$ to $11.6 \%$ ).

The number of coils used did not influence left lung perfusion ( $\mathrm{p}=0.24$, when comparing patients with one coil with those with multiple coils). Finally, there was no correlation between left lung perfusion and peak left pulmonary artery Doppler velocities, either for the entire study group $(r=0.27 ; \mathrm{p}=0.125)$ or for the patients with native ducts $(r=0.29$; $\mathrm{p}=0.124)$.
At a median follow up of 12 months, none of the patients had a ductal shunt or any increase in peak left pulmonary artery flow velocity on Doppler echocardiography.

\section{Discussion}

BACKGROUND

The aim of treatment for a persistent arterial duct is to achieve complete occlusion. The Rashkind double umbrella device falls short of the ideal, with a significant incidence of residual shunts, persisting for many years in some patients, ${ }^{1}$ and a need for further devices to achieve complete occlusion. In addition, large sized delivery catheters are required, and modifications of the technique of delivery by using smaller delivery systems add to the complexity of the procedure. ${ }^{10}$ Finally, follow up studies have shown a small but worrying incidence of compromised flow to the left lung, which seems to occur more often in smaller patients in whom large devices have been implanted, but has also been documented with the use of the smaller 12 $\mathrm{mm}$ diameter device ${ }^{23}$ in older patients.

\section{THE PRESENT STUDY}

In the present study we describe the use of detachable coils to occlude persistent ducts. The small delivery catheters $(4 \mathrm{~F}$ or $5 \mathrm{~F}$ ) facilitate delivery through either the femoral artery or vein, depending on the morphology of the duct and the ease with which it can be crossed in either direction. In previous studies describing coil occlusion procedures, a single coil was used in most cases, ${ }^{57}$ but there was a small but definite incidence of residual shunts. Where multiple non-detachable coils have been used, ${ }^{11}$ one follow up study of lung perfusion has been reported to date. ${ }^{12}$ In that study, two of four patients with Doppler detected gradients across the left pulmonary artery also had diminished left lung perfusion ( $<40 \%)$.

DEVICE PROTRUSION, DOPPLER VELOCITIES, AND LEFT LUNG PERFUSION

Device protrusion into the left pulmonary artery was associated with the use of multiple coils, which in turn was dependent on the minimum duct diameter measured at angiography. When three or more coils were used, there was always evidence of protrusion of the device into the left pulmonary artery on cross sectional echocardiography.

Although there was a significantly higher peak left pulmonary artery Doppler velocity in patients with coil protrusion, this did not correlate with left lung perfusion. The difference in left lung perfusion (mean difference of $1 \%$ ) was neither clinically nor statistically significant between patients with and without coil protrusion.

FOLLOW UP

We adopted a standardised follow up protocol, with lung perfusion studies three months after the occlusion procedure. Doppler echocardiography was performed on the same day as the lung perfusion study. There was no difference in the peak Doppler velocities measured immediately after occlusion and at follow up. It may be 
argued that lung perfusion studies should be repeated at longer term follow up. However, there is no reason to suppose that flow to either lung should become compromised with somatic growth and the resulting increase in the diameters of the branch pulmonary arteries.

LIMITATIONS

Preocclusion Doppler velocities in the left pulmonary artery were not systematically recorded for comparison with peak velocities after occlusion. The cut off value for normal left lung perfusion of $40 \%$ was chosen from previously reported studies. This has not been validated in our two laboratories. Ventilation scans were not performed simultaneously, to assess possible ventilation-perfusion mismatch following duct occlusion.

CONCLUSIONS

The use of multiple coils to achieve complete occlusion is associated with a low incidence of complications and no compromise of left pulmonary artery perfusion. Doppler echocardiography appears to be unreliable in assessing compromised flow to the left lung. Lung perfusion scans provide the best diagnostic test for assessing altered left pulmonary artery flow following ductal closure with a device.
1 Hosking MCK, Benson LN, Musewe N, et al. Transcatheter occlusion of the persistently patent ductus arteriosus: forty-month follow-up and prevalence of residual shunting. Circulation 1991;84:2313-17.

2 Nykanen DG, Hayes AM, Benson LN, et al. Transcatheter patent ductus arteriosus occlusion: application in the small child. F Am Coll Cardiol 1994;23:1666-70.

3 Dessy H, Hermus JPS, van den Heuvel F, et al. Echocardiographic and radionuclide pulmonary blood flow patterns after transcatheter closure of patent ductus arteriosus. Circulation 1996;94:126-9.

4 Fadley F, Al-Halees Z, Galal O, et al. Left pulmonary artery stenosis after transcatheter occlusion of persistent arterial duct. Lancet 1993;341:559-60.

5 Lloyd TR, Fedderly R, Mendelsohn AM, et al. Transcatheter occlusion of patent ductus arteriosus with Gianturco coils. Circulation 1993;88:1412-20.

6 Hijazi ZM, Geggel RL. Results of anterograde transcatheter closure of patent ductus arteriosus using single or multiple Gianturco coils. Am 7 Cardiol 1994;74:925-9.

7 Shim D, Fedderly RT, Beekman RH, et al. Follow-up of coil occlusion of patent ductus arteriosus. 7 Am Coll Cardiol 1996;28:207-11.

8 Krichenko A, Benson LN, Burrows P, et al. Angiographic classification of the isolated, persistently patent ductus arteriosus and implications for percutaneous catheter closure. Am f Cardiol 1989;63:877-80.

9 Tometzki AJP, Arnold R, Peart I, et al. Transcatheter occlusion of the patent ductus arteriosus with Cook detachable coils. Heart 1996;76:531-4.

10 Perry SB, Lock JE. Front-loading of double umbrella devices, a new technique for umbrella delivery for closing cardiovascular defects. Am f Cardiol 1992;70:917-20.

11 Hijazi ZM, Geggel RL. Transcatheter closure of large patent ductus arteriosus $(>4 \mathrm{~mm})$ with multiple Gianturco coils: immediate and mid-term results. Heart 1996;76:536-40.

12 Evangelista JK, Hijazi ZM, Geggel RL, et al. Effect of multiple coil closure of patent ductus arteriosus on blood flow to the left lung as determined by lung perfusion scans. $\mathrm{Am}$ f Cardiol 1997;80:242-4. 